\title{
Superstructure-based process synthesis and economic assessment under uncertainty for solid drug product manufacturing
}

\author{
Kensaku Matsunami ${ }^{1}$, Fabian Sternal ${ }^{1,2}$, Keita Yaginuma ${ }^{3}$, Shuichi Tanabe $^{3}$, Hiroshi Nakagawa ${ }^{3}$ and \\ Hirokazu Sugiyama ${ }^{1 *}$ (D)
}

\begin{abstract}
This paper presents a new method for process synthesis and economic assessment for solid drug product manufacturing, considering continuous manufacturing as a prominent process alternative. Of the three phases of drug development, phase II was targeted where the dosage form, formulation, and processing technology are determined. For a comprehensive alternative generation, a superstructure was developed that covered 9452 options for the unit level, which was combined with two options on the formulation strategy. The generated alternative was assessed by a net present value calculation model, which was adapted for dynamic cash flow consideration in the drug lifecycle. The model can incorporate uncertainty in the drug development and manufacturing in the result, and can perform global sensitivity analysis by Monte Carlo simulation. The method was demonstrated in a case study where two different scenarios regarding the price of the active pharmaceutical ingredient and the demand for the product were assumed. The results showed that when the demand and price are both low, the labor-related costs are dominant, and in the opposite case, the material-related costs become relevant. We also introduce the prototype version of the software "SoliDecision," by which the presented method was implemented for industrial application.
\end{abstract}

Keywords: Continuous manufacturing, Pharmaceutical manufacturing, Tablets, Formulation, Clinical development, Process design, Alternative generation, Decision-making, Monte Carlo simulation, Sensitivity analysis

\section{Introduction}

Solid drug products such as tablets or capsules are the most produced drugs, from among all types of drug products. As a result of the high level of research and development activity in this area, 31 new solid drugs were approved by the Food and Drug Administration of the US (FDA) in 2018 [1, 2]. Solid drug products are generally manufactured through a chain of powder-processing units with the active pharmaceutical ingredient (API) as the starting material. Examples of such units include mixing, granulation, drying, compression, and coating, which are connected linearly without recycling of the materials. Various alternatives exist on the unit level, such as direct compression, which skips granulation, and on the product

\footnotetext{
*Correspondence: sugiyama@chemsys.t.u-tokyo.ac.jp

${ }^{1}$ Department of Chemical System Engineering, The University of Tokyo, 7-3-1 Hongo, Bunkyo-ku, Tokyo 113-8656, Japan

Full list of author information is available at the end of the article
}

level, such as different formulation or dosage form. When designing a process, numerous alternatives need to be synthesized, analyzed, and evaluated to determine the more promising ones, in parallel with the clinical development, which is, by nature, uncertain.

The difficult task of process design has become more complex with the emergence of continuous manufacturing. The latter technology literally enables continuous processing of powder materials in the abovementioned units, which in the current practice are performed batchwise. There is a strong expectation in solid drug product manufacturing that continuous manufacturing would replace batch manufacturing [3]. From 2015 to date, the FDA has approved the use of continuous manufacturing for five products [4]. The potential benefits of continuous manufacturing are ease of scale-up, flexibility in demand change, and the capability of reducing the number of operators [5]. Ongoing discussions on the regulatory aspects 
such as control strategy $[6,7]$ are consolidating the way to implement this new technology, which promises to make some of the units or even the entire process continuous [8]. However, the progress in continuous manufacturing requires coping with the increased complexity in the process design.

Previous studies on process-related issues in solid drug product manufacturing have focused on specific production units, in particular, granulation and compression. The population balance model (PBM) has been widely applied to batch high-shear [9], fluidized-bed [10], and continuous twin-screw granulation [11]. Tamrakar and Ramachandran integrated PBM with the discrete element method (DEM) and computational fluid dynamics (CFD) for modeling fluidized-bed granulation [12]. Applications of DEM and other advanced simulation techniques were used for roller compaction [13], compression [14], and coating [15].

Several authors have covered the entire manufacturing process. Flowsheet models have been developed to predict dynamics for processes based on direct compression [16], dry granulation [17], and wet granulation [18]. Singh et al. developed a control strategy for dry granulation and implemented it into a process-wide flowsheet based on firstprinciples models [19]. In a case study, Schaber et al. assessed the economic performance of the integrated API and tablet manufacturing process, highlighting the benefits of continuous manufacturing [20]. Aigner et al. proposed a ranking-based economic comparison method between batch and continuous processes, which can be used in the early stages of process development [21]. For the later development stages, Matsunami et al. presented a method for selecting batch and continuous processes based on the net present operating cost [22]. By conducting industrial scale experiments, Matsunami et al. compared the product quality and process performance of both processes, providing insights for process-related decision-making [23]. However, the focus in these previous studies has been limited to specific technologies and products, such as wet granulation, and ethenzamide tablets, respectively.

Decision-making is always associated with uncertainty. Several authors tackled this relevant issue in drug development and manufacturing. Sundaramoorthy et al. performed capacity planning in continuous manufacturing based on a two-stage ("here-and-now" and "wait-and-see" decisions) stochastic programming approach [24, 25]. Marques et al. proposed a framework for product-launch planning based on multiobjective integer programming and Monte Carlo simulation (MCS) [26, 27]. Walther et al. applied MCS for biopharmaceutical manufacturing, to quantify the possible range of net present value (NPV) considering uncertain events such as success/failure in clinical trials [28]. For the pharmaceutical industry, MCSrelated techniques have a great potential for use in process and product development, which are by nature uncertain.
Another prerequisite for decision-making is a holistic viewpoint. This is particularly important for solid drug manufacturing, where new technologies such as continuous manufacturing are intensively developed. In the field of process systems engineering (PSE), superstructures that consider various alternatives simultaneously have been studied. Prominent examples include the flowsheet superstructure [29], state-task and state-equipment networks [30, 31], stepwise superstructure [32], and the processing step-interval network [33]. However, the application of these otherwise useful techniques for pharmaceutical manufacturing processes is still limited.

In this work, we present a new method for process synthesis and economic assessment for solid drug product manufacturing, considering continuous manufacturing as a prominent process alternative. The main aim was to provide a new mechanism for exhaustive enumeration and economic assessment of process alternatives considering the uncertainties in the product and process development. Of the three phases of drug development, phase II was targeted, where the dosage form, formulation, and processing technology are determined. A superstructure was developed for the generation of a comprehensive alternative that covers numerous options at the unit level; this superstructure was combined with the formulation strategy options. The generated alternative was assessed using an MCS-based model for calculating NPV, followed by a global sensitivity analysis. The workflow was demonstrated in a case study where two different scenarios regarding API price and demand were assumed. We also introduce the prototype version of the software "SoliDecision," which implemented the presented method for an industrial application. An earlier version of the process synthesis and stochastic economic evaluation was presented at the 13th International Symposium on Process Systems Engineering [34].

\section{Method \\ Superstructure-based process synthesis Superstructure representation}

We define a superstructure representation of solid drug product manufacturing processes (Fig. 1). The method of Wu et al. [35], which defines units, ports, and streams, was adopted. The units are categorized into three types, source, sink, and general units, which were used to represent the provision of raw materials, collection of final products, and unit operations, respectively (see Tables 1 and 2 for the definitions). The ports are the interfaces between the units, which, in this work, represent materials such as granules. The presence and absence of API in the stream were defined with solid and dotted arrows, respectively. Streams were defined that skip a certain unit(s) to describe the choice of performing the unit(s), e.g., direct compaction that does not involve roller compaction $\left(\mathrm{U}_{9}\right)$, wet granulation $\left(\mathrm{U}_{10}\right.$ and $\left.\mathrm{U}_{11}\right)$, drying $\left(\mathrm{U}_{12}\right)$, and milling $\left(\mathrm{U}_{13}\right)$. A 


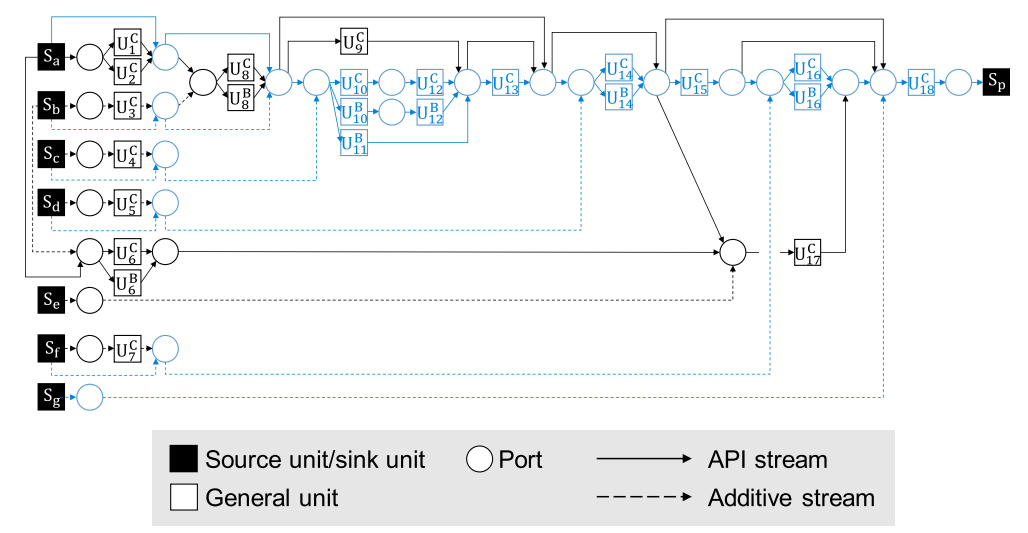

Fig. 1 Developed superstructure for solid drug product manufacturing processes

process alternative is defined as a combination of the streams, ports, and units from the source to the sink units (i.e., a combination of raw materials, processing technologies, and dosage form). The process is linear, i.e., there is no recycling, and the API is never split into multiple streams in an alternative route.

The key consideration here was to reflect on the characteristics of the process, namely, the dependence of the used materials on the process alternative. For example, when wet granulation $\left(U_{10}\right.$ and $\left.U_{11}\right)$ is selected, water must be included in the ports before the unit and in the source $\left(\mathrm{S}_{\mathrm{c}}\right)$. Likewise, the presence of coating $\left(\mathrm{U}_{16}\right)$, encapsulation $\left(\mathrm{U}_{17}\right)$, or packaging $\left(\mathrm{U}_{18}\right)$ will require coating agents, capsules, or packages in the system, respectively. The method of Wu et al. [35] can explicitly define the presence and composition of the materials and thus was suitable for our purpose.

\section{Comprehensive alternative generation}

The superstructure in Fig. 1 was developed based on the literature survey as well as the expert knowledge of the industrial coauthors. The superscripts of the general

Table 1 Description of the source and sink units

\begin{tabular}{ll}
\hline $\begin{array}{l}\text { Name of source/sink } \\
\text { unit }\end{array}$ & Description \\
\hline$S_{a}$ & Provision of API \\
$S_{b}$ & $\begin{array}{l}\text { Provision of additives (e.g., excipients and/or } \\
\text { disintegrants) }\end{array}$ \\
$S_{c}$ & Provision of aqueous binder solution \\
$S_{d}$ & Provision of additives \\
$S_{e}$ & Provision of capsules \\
$S_{f}$ & Provision of coating agents \\
$S_{g}$ & Provision of packages (e.g., blister packages) \\
$S_{p}$ & Collection of solid drug product \\
\hline
\end{tabular}

units specify whether the operation is batch (B) or continuous (C). In total, 9452 process alternatives could be defined in Fig. 1, and their breakdown is presented in Additional file 1 . The number of alternatives was calculated by separating the superstructure into parts (see Additional file 1 for the details). This superstructure can be updated by adding new units and/or combinations of units when they become of interest in the analysis.

In this study, the process alternative was denoted as "continuous technology" if all unit operations are interconnected with units of the continuous operation mode. Consequently, the alternative will have a single manufacturing rate for the entire process. If the batch mode is used in any unit, the alternative is regarded as "batch technology," i.e., all units are performed stepwise.

Besides the process alternatives, the formulation concept for different doses was considered. In general, in clinical development, at least two doses are produced, for which two options are available. One is "proportional dosage," which means that all doses have the same composition ratio with different weights. The other is "common dosage" which means that all doses have the same weight but the composition ratios differ. Combinations of these two are also possible. Depending on this choice, the required amounts of the raw materials for the products and the placebos are different, and the consequential economic performance is affected. In this work, we considered the two options of proportional and common dosage as the choice of formulation strategy.

In this study, an alternative was defined as a combination of the process alternative and formulation strategy, i.e., $9452 \times 2=18,904$ alternatives can be enumerated from the superstructure and assessed one by one. In practice, the generation of alternatives could start with a reduced number of alternatives, due to case-specific reasons. Examples of the constraints are the resource availability for development and production, the characteristics of the 
Table 2 Description of the general units

\begin{tabular}{ll}
\hline General unit ID & Description \\
\hline$U_{1}$ & Size reduction \\
$U_{2}$ & Spray drying \\
$U_{3}$ & Size reduction \\
$U_{4}$ & Size reduction \\
$U_{5}$ & Size reduction \\
$U_{6}$ & Dissolving \\
$U_{7}$ & Size reduction \\
$U_{8}$ & Mixing \\
$U_{9}$ & Roller compaction \\
$U_{10}$ & Wet granulation without drying \\
$U_{11}$ & (e.g., high-shear granulation) \\
$U_{12}$ & Wet granulation and drying \\
$U_{13}$ & (e.g., fluidized-bed granulation) \\
$U_{14}$ & Drying \\
$U_{15}$ & Milling \\
$U_{16}$ & Blending \\
$U_{17}$ & Compression \\
$U_{18}$ & Coating \\
\hline
\end{tabular}

powder materials, or the company preference based on past experience and/or market characteristics. In the case study presented here, we considered three process alternatives using wet granulation $\left(\mathrm{U}_{10}^{\mathrm{C}}, \mathrm{U}_{10}^{\mathrm{B}}\right.$, and $\left.\mathrm{U}_{11}^{\mathrm{B}}\right)$ and two formulation strategies (common and proportional), i.e., six alternatives in total. The parts in Fig. 1 marked in blue are the considered alternatives. The choice was because our drug product of interest was suitable for wet granulation.

\section{Economic assessment model}

\section{Overview of economic assessment}

An overview of the cash flow in the drug lifecycle is illustrated in Fig. 2. The decision stage $(\tau=0)$ is the beginning of phase II in clinical development, where the dosage form, formulation, and processing technology are determined. The design problem was defined as "given the product formulation, find the best process alternatives (a combination of dosage form, processing technology, and raw material) and formulation strategy (proportional or common) that maximizes the economic performance." The economic objective function, $N P V(l)[\$]$ was defined as a function of alternative $l$ (see Eq. (1)).

$$
\begin{aligned}
N P V(l)= & -\sum_{\tau=0}^{\tau_{3}} \frac{C_{\text {dev }}(\tau)}{(1+r)^{\tau}}\left|-\sum_{l=0}^{\tau_{\text {prod }}} \frac{C_{\text {invest }}(\tau)}{(1+r)^{\tau}}\right|_{l} \\
& +\sum_{\tau=\tau_{\text {lau }}}^{\tau_{\text {prod }}} \frac{C_{\text {sales }}(\tau)-C_{o p}(\tau)}{(1+r)^{\tau}} \mid,
\end{aligned}
$$

where $C_{\text {dev }}(\tau)\left[\$ \mathrm{yr}^{-1}\right], C_{\text {invest }}(\tau)\left[\$ \mathrm{yr}^{-1}\right], C_{\text {sales }}(\tau)\left[\$ \mathrm{yr}^{-1}\right]$, $C_{\mathrm{op}}(\tau)\left[\$ \mathrm{yr}^{-1}\right]$, and $r[-]$ (dimensionless) represent the development cost, investment cost, sales, and operating cost in $\tau$ years after the decision stage, and the interest rate, respectively. The parameters $\tau_{j}$ [yr], $\tau_{\text {inv }}[\mathrm{yr}], \tau_{\text {lau }}[\mathrm{yr}]$, and $\tau_{\text {prod }}[\mathrm{yr}]$ represent the periods from the decision stage to the clinical trials at phase $j$ (phase III in Eq. (1)), the investment in production facilities (e.g., the continuous manufacturing machine), the product launch, and the end of the commercial production, respectively. This indicator was extended from the conventional NPV [36] by considering the cash flow in the drug lifecycle, in particular, the development cost $C_{\mathrm{dev}}$. For the operating cost, $C_{\mathrm{op}}(\tau)$, the existing economic evaluation model proposed by our group [22] was used. In case continuous technology is considered as the alternative, an optimization algorithm is run to specify the validated run time to maximize the third term in Eq. (1) (see [22] for details).

The design problem can be expressed as shown in Eq. (2):

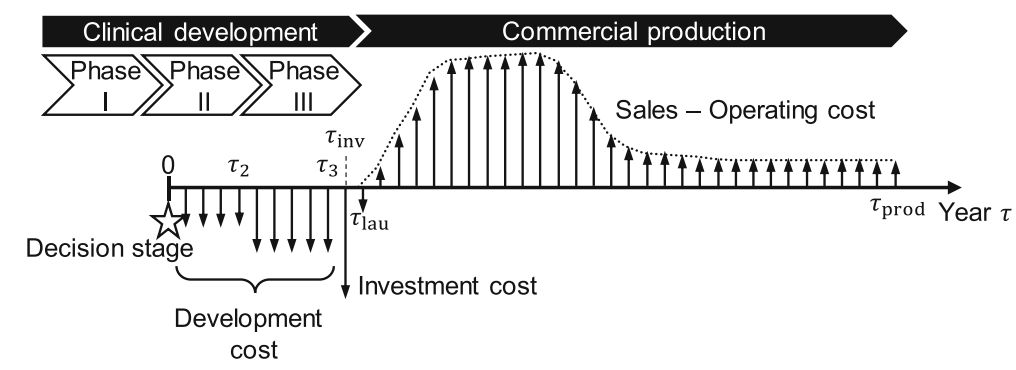

Fig. 2 Overview of cash flow in the drug lifecycle with indication of the decision stage considered in the study 


$$
\max E_{\boldsymbol{\theta}}(N P V(l))
$$

s.t.

$$
E_{\boldsymbol{\theta}}(N P V(l))>0
$$

(Mass balance constraints)

(Processing time constraints)

(Pharma-specific constraints)

where the objective function is the expected value of $\mathrm{NPV}$, the design variable is alternative $l$, and the parameter $\boldsymbol{\theta}$ represents the vector of uncertainty parameters. The first constraint serves as the rejection criterion for an alternative. The second, third, and fourth constraints consider the mass balance of raw materials and products/ losses, time-related constraints, e.g., the validated run time for continuous technology, and pharma-specific aspects, e.g., safety stock, respectively (see [22] for the details).

An additional mechanism was defined for investigating the superiority of one alternative over another. Eq. (3) defines the differences in $N P V$ between alternatives $l_{1}$ and $l_{2}, \Delta N P V_{l_{1}, l_{2}}[\$]$.

$$
\Delta N P V_{l_{1}, l_{2}}=N P V\left(l_{1}\right)-N P V\left(l_{2}\right)
$$

The area of $\triangle N P V_{l_{1}, l_{2}}>0$ provides the probability that alternative $l_{1}$ becomes preferable to $l_{2}$.

\section{Details of economic assessment}

The indicator shown in Eq. (1) distinguishes between the following three development-related tasks: development of formulation and process, scale-up study, and production of clinical investigational drugs. In the formulation and process development, the type of additives and process parameters are usually determined using small-scale equipment. Scale-up studies are then conducted with larger equipment. In the case of continuous technology, the ease of scale-up becomes advantageous. Finally, clinical investigational drugs are produced using the determined formulation and processes, to fulfill the required amount given by clinical-trial examiners. Based on these considerations, the development cost, $C_{\mathrm{dev}}\left(\tau_{j}\right)$, was defined as shown in Eq. (4).

$$
\begin{aligned}
C_{\mathrm{dev}}\left(\tau_{j}\right)= & \text { Material cost }+ \text { Labor cost } \\
= & \left(C_{\text {material,process }}^{j}+C_{\text {material,scale }}^{j}+C_{\text {material,clinical }}^{j}\right) \\
& +\left(C_{\text {labor,process }}^{j}+C_{\text {labor,scale }}^{j}+C_{\text {labor,clinical }}^{j}\right) .
\end{aligned}
$$

The parameters $C_{\text {material,process }}^{j}\left[\$ \mathrm{yr}^{-1}\right], C_{\text {material,scale }}^{j}[\$$ $\left.\mathrm{yr}^{-1}\right], \quad C_{\text {material,clinical }}^{j}\left[\$ \mathrm{yr}^{-1}\right], C_{\text {labor,process }}^{j}\left[\$ \mathrm{yr}^{-1}\right]$,
$C_{\text {labor,scale }}^{j}\left[\$ \mathrm{yr}^{-1}\right]$, and $C_{\text {labor,clinical }}^{j}\left[\$ \mathrm{yr}^{-1}\right]$ represent the material and labor costs for formulation and process development, scale-up study, and investigational drug production in phase $j$, respectively. The characteristics of the alternative are reflected in this equation, e.g., a credit for scale-up-free nature can be given when continuous technology is adopted.

The sales, $C_{\text {sales }}(\tau)$, was formulated as shown in Eq. (5):

$$
C_{\text {sales }}(\tau)=\sum_{h} C_{\text {drug }}^{h} N_{\text {demand }}^{h}(\tau),
$$

where $C_{\mathrm{drug}}^{h}\left[\$(\text { dosage unit })^{-1}\right]$ and $N_{\text {demand }}^{h}(\tau)$ [(dosage unit) $\mathrm{yr}^{-1}$ ] represent the selling price and the demand amount of the product with formulation $h$, respectively.

The operating cost, $C_{\mathrm{op}}(\tau)$, was defined on the basis of our previous work [22] as:

$$
\begin{aligned}
C_{\mathrm{op}}(\tau)= & \text { Material cost }+ \text { Disposal cost }+ \text { Labor cost }+ \text { Utility cost } \\
& + \text { Capacity cost }=\left\{\sum_{k} C_{\text {material }, k}\left(M_{\text {product }, k}(\tau)+M_{\text {loss }, k}(\tau)\right)\right. \\
& \left.+C_{\text {material,solvent }} M_{\text {solvent }}(\tau)+C_{\text {test }}(\tau)\right\}+C_{\text {disposal }} \sum_{k} M_{\text {loss }, k}(\tau) \\
& +C_{\text {labor }}\left(W_{\text {manu facturing }}(\tau)+W_{\text {cleaning }}(\tau)+W_{\text {testing }}(\tau)\right. \\
& \left.+W_{\mathrm{PAT}}(\tau)\right)+C_{\mathrm{HVAC}} A T_{\mathrm{HVAC}}(\tau)+C_{\text {capacity }}(\tau) .
\end{aligned}
$$

The parameters $C_{\text {material, } k}\left[\$ \mathrm{~kg}^{-1}\right], C_{\text {material, solvent }}[\$$ $\left.\mathrm{kg}^{-1}\right], C_{\text {test }}(\tau)\left[\$ \mathrm{yr}^{-1}\right], M_{\text {product, } k}(\tau)\left[\mathrm{kg} \mathrm{yr}^{-1}\right], M_{\text {loss, } k}(\tau)$ [ $\left.\mathrm{kg} \mathrm{yr}^{-1}\right]$, and $M_{\text {solvent }}(\tau)\left[\mathrm{kg} \mathrm{yr}^{-1}\right]$ represent the cost of raw material $k$, the raw material cost of solvent, the cost of materials for testing, the annual amount of material $k$ used to make the product, amount of annual losses of material $k$, and amount of solvent used annually, respectively. Examples of losses are sampling, sticking, or discards during start-up. A solvent is used to dissolve the binder or coating agent, and water is used typically. The parameter $C_{\text {disposal }}\left[\$ \mathrm{~kg}^{-1}\right]$ represents the cost to dispose of a unit amount of loss, which was assumed to be independent of the type of materials. The parameter $C_{\text {labor }}\left[\$\right.$ person $\left.^{-1} \mathrm{~h}^{-1}\right]$ is the labor rate and the parameters $W_{\text {manufacturing }}(\tau)$ [person $\mathrm{h} \mathrm{yr}^{-1}$ ], $W_{\text {cleaning }}(\tau)$ [person $\mathrm{h} \mathrm{yr}^{-1}$ ], $W_{\text {testing }}(\tau)$ [person $\mathrm{h} \mathrm{yr}^{-1}$ ], and $W_{\operatorname{PAT}}(\tau)$ [person $\mathrm{h} \mathrm{yr}^{-1}$ ] represent the annual person-hours for manufacturing, cleaning, testing, and for process analytical technology (PAT) maintenance, respectively. The parameters $C_{\text {HVAC }}\left[\$ \mathrm{~m}^{-2} \mathrm{~h}^{-1}\right], A\left[\mathrm{~m}^{2}\right], T_{\text {HVAC }}(\tau)\left[\mathrm{h} \mathrm{yr}^{-1}\right]$ represent the heating, ventilation, and air conditioning (HVAC) cost, manufacturing area that is covered by HVAC, and HVAC running time, respectively. The parameter $C_{\text {capaci- }}$ ty $(\tau)\left[\$ \mathrm{yr}^{-1}\right]$ represents capacity cost, i.e., the loss of profits from capacity displaced by the new product as an additional operating cost. The original model in [22] was only for comparing the batch and continuous 
technologies; in this work, we extended the model to assess all possible process alternatives. Solid drug product manufacturing is a linear process without recycling, and thus the mass balance is simple. The term ( $M_{\text {product, }}$ $\left.{ }_{k}(\tau)+M_{\text {loss, } k}(\tau)\right)$ corresponds to the amount of raw material. The solvent (typically water) is dried during the process, and thus the term $M_{\text {solvent }}(\tau)$ is not included in the mass balance. In the calculation $M_{\text {loss, } k}(\tau)$ can be specified according to our previous paper [22] with the values provided by the industrial coauthors.

\section{MCS}

MCS can quantify various types of uncertainty in clinical development and commercial production by defining the probability density function (PDF) of the input parameters. In the decision stage, i.e., the beginning of phase II, the parameters in the abovementioned models are still open. Moreover, the success of the drug is uncertain. We defined the uncertainty parameters that are subject to a global sensitivity analysis (see Table 3). Normally, the variables such as continuous manufacturing rate and start-up operation time can be determined at later development stages through experimental investigations. These variables were classified as internal variables. The variables such as demand amount and success/failure of clinical development are given as external constraints, also at later stages.

In this work, we used a triangular distribution as the PDF for the parameters with ranges/multiple values, which specifies a distribution with the minimum, maximum, and peak values of parameters. The choice of the distribution

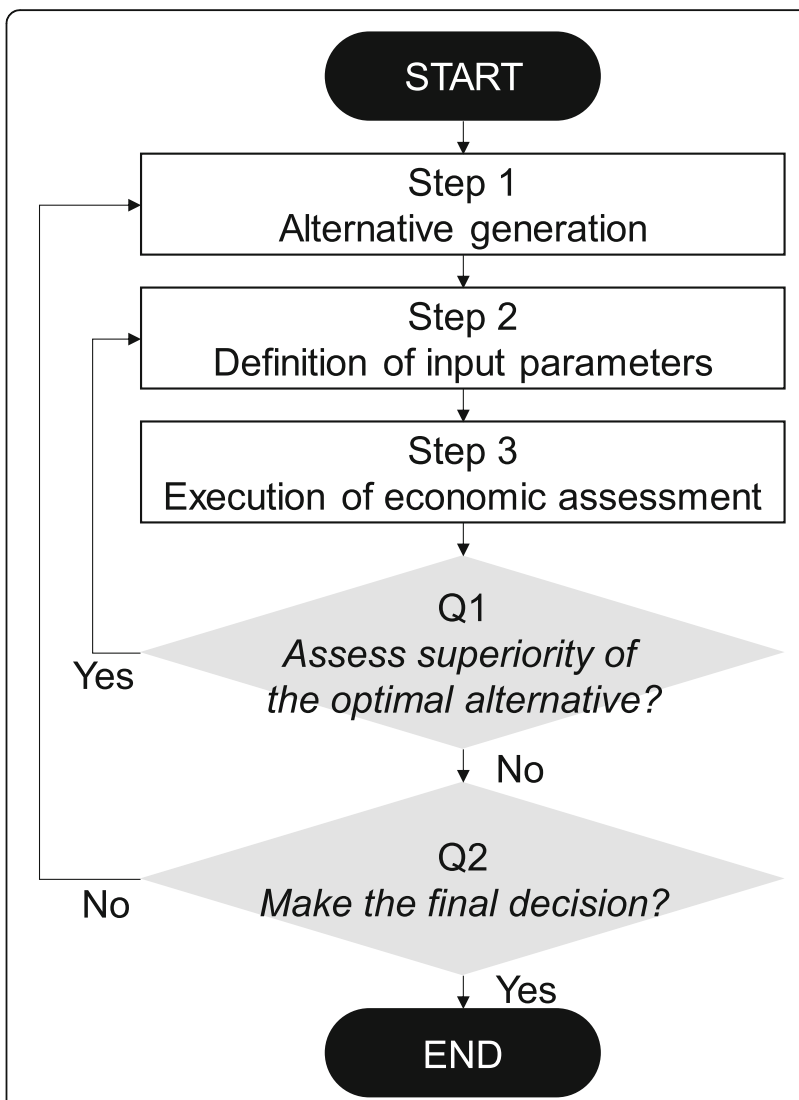

Fig. 3 Workflow for applying the developed mechanisms

Table 3 Overview of the uncertainty parameters

\begin{tabular}{|c|c|c|}
\hline Category & Type of variable & $\begin{array}{l}\text { Number of parameters } \\
\text { used in the case study }\end{array}$ \\
\hline \multicolumn{3}{|l|}{ Internal variables determined at later stages } \\
\hline Dosage unit size and composition & Continuous & 9 \\
\hline Number of PATs installed & Continuous & 2 \\
\hline Manufacturing space & Continuous & 2 \\
\hline Manufacturing rate in continuous technology & Continuous & 1 \\
\hline Time related to production, cleaning, and test & Continuous & 19 \\
\hline Losses & Continuous & 11 \\
\hline Number of operators & Discrete & 21 \\
\hline Number of lots in one campaign manufacturing & Discrete & 2 \\
\hline \multicolumn{3}{|l|}{ External variables given at later stages } \\
\hline Raw material price & Continuous & 7 \\
\hline Demand/required amount & Discrete & 6 \\
\hline Man-hours of work in the maintenance of PAT per one PAT & Continuous & 1 \\
\hline Disposal/HVAC cost & Continuous & 2 \\
\hline Drug price & Continuous & 1 \\
\hline Success/failure of clinical development & Categorical & 1 \\
\hline
\end{tabular}


Table 4 Values of the parameters varied in scenarios

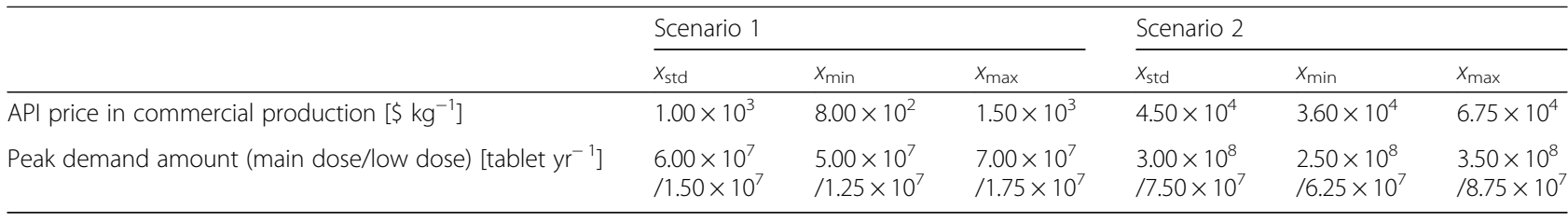

was because (i) the triangular distribution can be asymmetric, (ii) the upper and lower ends can be specified, and most importantly, (iii) the distribution can be specified with the information available in phase II.

For the continuous variables such as the manufacturing rate, the $\operatorname{PDF} f_{1}(x)$ was defined as shown in Eq. (7).

$$
f_{1}(x)=\left\{\begin{array}{c}
\frac{2\left(x-x_{\min }\right)}{\left(x_{\max }-x_{\min }\right)\left(x_{\mathrm{std}}-x_{\min }\right)} \mid x_{\min } \leq x \leq x_{\mathrm{std}} \\
\frac{2\left(x_{\max }-x\right)}{\left(x_{\max }-x_{\min }\right)\left(x_{\max }-x_{\mathrm{std}}\right)} \mid x_{\mathrm{std}} \leq x \leq x_{\max } \\
0 \mid x<x_{\min }, x>x_{\max }
\end{array},\right.
$$

where $x_{\min }, x_{\max }$, and $x_{\text {std }}$ represent the minimum, maximum, and standard (i.e., peak) values of an input parameter, respectively. For integer variables such as the number of operators, a discrete triangular distribution [37], $f_{2}(x)$, was used, (Eq. (8)). For the interval of the discrete parameters, the unit value was used.

$$
f_{2}(x)=\left\{\begin{array}{c}
\frac{2\left(x-x_{\min }+1\right)}{\left(x_{\max }-x_{\min }+2\right)\left(x_{\mathrm{std}}-x_{\min }+1\right)} \mid x_{\min } \leq x \leq x_{\mathrm{std}} \\
\frac{2\left(x_{\max }-x+1\right)}{\left(x_{\max }-x_{\min }+2\right)\left(x_{\max }-x_{\mathrm{std}}+1\right)} \mid x_{\mathrm{std}} \leq x \leq x_{\max } \\
0 \mid x<x_{\min }, x>x_{\max }
\end{array}\right.
$$

Regarding the success or failure of the product launch, which is a categorical variable, the discrete (not necessarily triangular) distribution $f_{3}\left(x_{\text {success }}\right)$ was formulated as Eq. (9).

$$
f_{3}\left(x_{\text {success }}\right)=\left\{\begin{array}{c}
p_{2} \mid x_{\text {success }}=0 \\
p_{3} \mid x_{\text {success }}=1 \\
1-p_{2}-p_{3} \mid x_{\text {success }}=2
\end{array},\right.
$$

where $p_{2}[-]$ and $p_{3}[-]$ represent the probability that clinical development fails at phases II and III, respectively. The parameter $x_{\text {success }}[-]$ represents the status of the clinical development, which consists of 0 (development fails at phase II), 1 (development fails at phase III), and 2 (development is successful, followed by product launch).

An MCS can be run using the defined distributions. In this study, the iteration was set as 10,000 and Latin hypercube sampling (LHS) [38] was used as the sampling method. In one iteration, a set of values between 0 and $1, p_{\mathrm{LHS}}$, was generated for all parameters of all alternatives, which were then converted to a set of actual parameter values, $x_{\text {sample }}$, using the inverse cumulative distribution functions. The relationship between $x_{\text {sample }}$ and $p_{\mathrm{LHS}}$, can be formulated as Eq. (10).

$$
p_{\mathrm{LHS}}=\frac{\int_{-\infty}^{x_{\text {sample }}} f(x) \mathrm{d} x}{\int_{-\infty}^{\infty} f(x) \mathrm{d} x}
$$

\section{Global sensitivity analysis}

Global sensitivity analysis can identify critical parameters for decision-making. We used the Spearman rank correlation coefficient (RCC), $\rho_{x}[-][39,40]$ (Eq. (11)), as follows.

Table 5 Standard values of tablet weight and composition ratio applied to scenarios

\begin{tabular}{llll}
\hline & Main dose & Low dose (proportional) & Low dose (common) \\
\hline Tablet weight $\left[\mathrm{kg} \mathrm{tablet}^{-1}\right]$ & $3.0 \times 10^{-4}$ & $6.0 \times 10^{-5}$ & $3.0 \times 10^{-4}$ \\
Composition ratio $[-]$ & & & 0.060 \\
API & 0.30 & 0.30 & 0.80 \\
Excipient & 0.56 & 0.56 & 0.10 \\
Disintegrant & 0.10 & 0.10 & 0.015 \\
Binder & 0.015 & 0.0050 & 0.0050 \\
Lubricant & 0.0050 & 0.020 & 0.020 \\
Coating agent & 0.020 & & \\
\hline
\end{tabular}


Table 6 Overview of the generated alternatives

\begin{tabular}{|c|c|c|c|}
\hline Alternative number & Combination of the general units in Fig. 1 & Technology & Formulation strategy \\
\hline 1 & $U_{10}^{C}, U_{12}^{C}, U_{13}, \cup_{14}^{C}, U_{15}, U_{16}^{C}, U_{18}$ & Continuous & Proportional \\
\hline 2 & $U_{10}^{C}, U_{12}^{C}, U_{13}, U_{14}^{C}, U_{15}, U_{16}^{C}, U_{18}$ & Continuous & Common \\
\hline 3 & $U_{10}^{B}, U_{12}^{B}, U_{13}, \cup_{14}^{B}, U_{15}, U_{16}^{B}, U_{18}$ & Batch (high-shear) & Proportional \\
\hline 4 & $U_{10}^{B}, U_{12}^{B}, U_{13}, \cup_{14}^{B}, \cup_{15}, \cup_{16}^{B}, U_{18}$ & Batch (high-shear) & Common \\
\hline 5 & $U_{11}^{B}, U_{13}, U_{14}^{B}, U_{15}, U_{16}^{B}, U_{18}$ & Batch (fluidized-bed) & Proportional \\
\hline 6 & $U_{11}^{B}, U_{13}, U_{14}^{B}, U_{15}, U_{16}^{B}, U_{18}$ & Batch (fluidized-bed) & Common \\
\hline
\end{tabular}

$$
\rho_{x}=1-\frac{6 \sum d^{2}}{N\left(N^{2}-1\right)}
$$

where $N[-]$ and $d[-]$ represent the iteration number and the difference between the ranks of the parameters $x$ and $\triangle N P V_{l_{1}, l_{2}}$, respectively. In this work, the value of $\rho_{x}$ was set as 0 , in the case where the $p$-value for $\rho_{x}$ was greater than 0.05 . For the parameters associated with commercial production, the results of the iterations in which $x_{\text {success }}=2$ were extracted from the 10,000 datasets and were used in the sensitivity analysis. For the critical parameters, a what-if analysis was performed by changing the PDF to judge whether these parameters would affect the decision. The significance of the difference of $\triangle N P V_{l_{1}, l_{2}}$ was confirmed by the KolmogorovSmirnov test $[41,42]$ by randomly sampling 100 data

Table 7 Lot size and amount of materials used in clinical development

\begin{tabular}{|c|c|c|c|c|c|}
\hline & Phase & Main/low dose & Technology & Lot size & Quantity \\
\hline Formulation and process development (formulation) & $\|\&\|$ & Main & $\begin{array}{l}\text { Batch and } \\
\text { continuous }\end{array}$ & $1 \mathrm{~kg} \mathrm{lot}^{-1}$ & 30 lots \\
\hline Formulation and process development (formulation) & $\|\&\|$ & Low (proportional) & $\begin{array}{l}\text { Batch and } \\
\text { continuous }\end{array}$ & - & 0 \\
\hline Formulation and process development (formulation) & $\|\&\| \|$ & Low (common) & $\begin{array}{l}\text { Batch and } \\
\text { continuous }\end{array}$ & $1 \mathrm{~kg} \mathrm{lot}^{-1}$ & 30 lots \\
\hline $\begin{array}{l}\text { Formulation and process development (pre-scale- } \\
\text { up) }\end{array}$ & $\|\&\|$ & Main & $\begin{array}{l}\text { Batch and } \\
\text { continuous }\end{array}$ & $5 \mathrm{~kg} \mathrm{lot}^{-1}$ & 4 lots \\
\hline $\begin{array}{l}\text { Formulation and process development (pre-scale- } \\
\text { up) }\end{array}$ & $\|\&\| \|$ & Low (proportional) & $\begin{array}{l}\text { Batch and } \\
\text { continuous }\end{array}$ & - & 0 \\
\hline $\begin{array}{l}\text { Formulation and process development (pre-scale- } \\
\text { up) }\end{array}$ & $\|\&\| \|$ & Low (common) & $\begin{array}{l}\text { Batch and } \\
\text { continuous }\end{array}$ & $5 \mathrm{~kg} \mathrm{lot}^{-1}$ & 4 lots \\
\hline Scale-up study & $\|$ & Main & Batch & $30 \mathrm{~kg} \mathrm{lot}^{-1}$ & 4 lots \\
\hline Scale-up study & $\|$ & Low (proportional) & Batch & $30 \mathrm{~kg} \mathrm{lot}^{-1}$ & 2 lots \\
\hline Scale-up study & $\|$ & Low (common) & Batch & $30 \mathrm{~kg} \mathrm{lot}^{-1}$ & 4 lots \\
\hline Scale-up study & III & Main & Batch & $\begin{array}{l}100 \mathrm{~kg} \\
\mathrm{lot}^{-1}\end{array}$ & 4 lots \\
\hline Scale-up study & III & Low (proportional) & Batch & $\begin{array}{l}100 \mathrm{~kg} \\
\mathrm{lot}^{-1}\end{array}$ & 2 lots \\
\hline Scale-up study & III & Low (common) & Batch & $\begin{array}{l}100 \mathrm{~kg} \\
\mathrm{lot}^{-1}\end{array}$ & 4 lots \\
\hline Scale-up study & $\|\&\| \|$ & Both & Continuous & - & \\
\hline Investigational drug production & $\|$ & Main & $\begin{array}{l}\text { Batch and } \\
\text { continuous }\end{array}$ & $30 \mathrm{~kg} \mathrm{lot}^{-1}$ & $\begin{array}{l}2.0 \times 10^{5} \\
\text { tablets }^{\mathrm{a}}\end{array}$ \\
\hline Investigational drug production & $\|$ & $\begin{array}{l}\text { Low (proportional and } \\
\text { common) }\end{array}$ & $\begin{array}{l}\text { Batch and } \\
\text { continuous }\end{array}$ & $30 \mathrm{~kg} \mathrm{lot}^{-1}$ & $\begin{array}{l}5.0 \times 10^{4} \\
\text { tablets }^{\mathrm{a}}\end{array}$ \\
\hline Investigational drug production & III & Main & $\begin{array}{l}\text { Batch and } \\
\text { continuous }\end{array}$ & $\begin{array}{l}100 \mathrm{~kg} \\
\mathrm{lot}^{-1}\end{array}$ & $\begin{array}{l}8.0 \times 10^{5} \\
\text { tablets }^{\mathrm{a}}\end{array}$ \\
\hline Investigational drug production & III & $\begin{array}{l}\text { Low (proportional and } \\
\text { common) }\end{array}$ & $\begin{array}{l}\text { Batch and } \\
\text { continuous }\end{array}$ & $\begin{array}{l}100 \mathrm{~kg} \\
\mathrm{lot}^{-1}\end{array}$ & $\begin{array}{l}2.0 \times 10^{5} \\
\text { tablets }^{\mathrm{a}}\end{array}$ \\
\hline
\end{tabular}

The quantity shown in the table is the standard value of the expected required quantity of tablets for clinical trials. In addition, the same amount of placebo is produced for the main and low doses in proportional dosage. For the low dose in common dosage, additional production of placebo is not required because the tablet size is the same as the main dose 


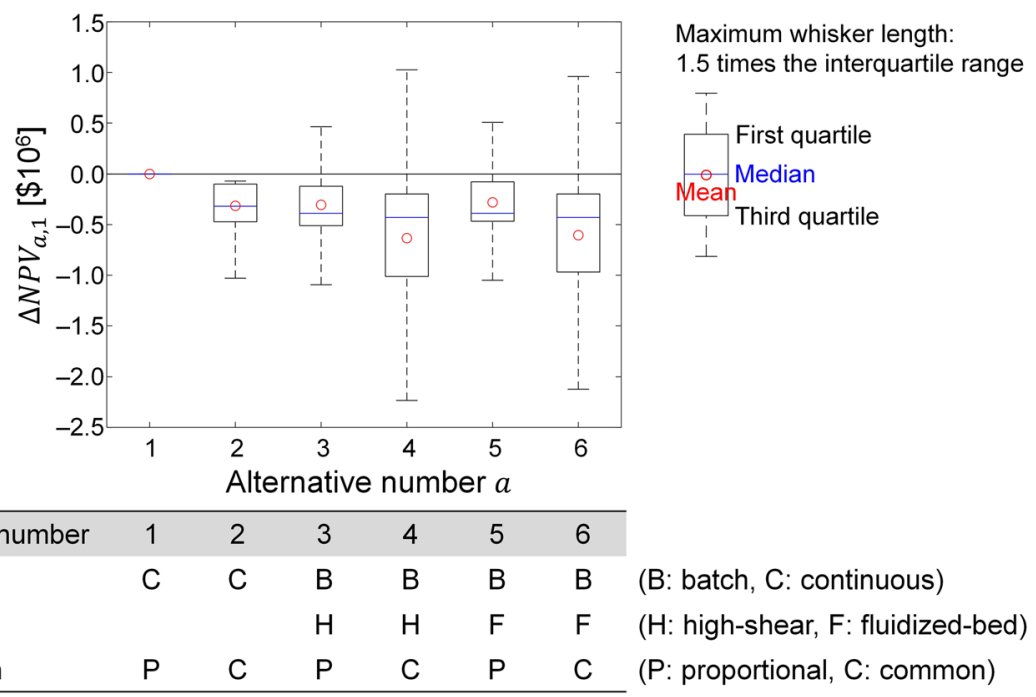

Fig. 4 Results of $\triangle N P V_{a, 1}$ in Scenario 1

from the distributions before and after changing the critical parameter [43].

\section{Workflow for general application}

Figure 3 presents the workflow for the general application of the mechanisms presented above. In Step 1, alternatives are generated using the superstructure, followed by the specification of the PDFs for the input parameters in Step 2. In Step 3, each alternative is assessed using the NPV (see Eq. 1), to identify the optimal one (see Eq. 2). The probability of the superiority of the latter to other alternatives (see Eq. 3 ) is also obtained. If the superiority of the optimal alternative needs to be investigated further (Q1), Steps 2 and 3 are repeated, particularly the sensitivity and what-if analyses. If the obtained information/understanding is sufficient for the final decision $(\mathrm{Q} 2)$, the analysis can be concluded.

\section{Results and discussion}

\section{Scenario setting}

To confirm its effectiveness and to obtain practical insights, the presented method was demonstrated in two scenarios. Scenario 1 was the case in which the API was inexpensive and the product demand was small, whereas, in Scenario 2, an expensive API and large demand were assumed (see Table 4). The decision stage was the beginning of phase II (see Fig. 2). It was assumed that two doses of tablets with high and low API contents were required, with defining the former as "main dose" and the latter as "low dose." As Step 1 of the workflow (see Fig. 3), we focused on wet granulation and generated three process alternatives (the blue highlights in Fig. 1). In addition, the choice of formulation strategy, i.e., proportional and common dosages, was considered (see Table 5). The overview of the six generated alternatives is presented in Table 6 . The alternatives 1 and 2 represent the continuous technology with proportional and common dosages, respectively. For batch technology, high-shear granulation was assumed for alternatives 3 and 4, and fluidized-bed granulation for alternatives 5 and 6 . The low-dose formulation was changed depending on the strategy of proportional or common dosages while the formulation of the main dose was fixed.

For Step 2, the input parameters, except for the demand amount and the API price, were defined as the

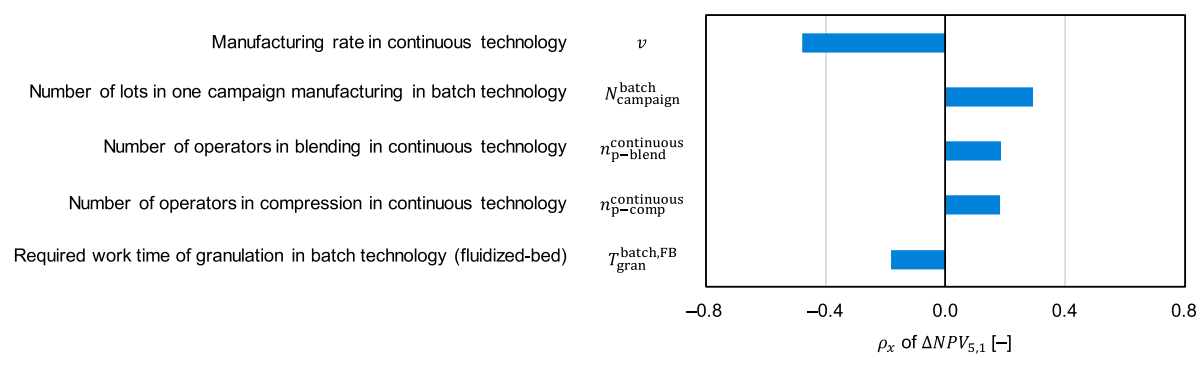

Fig. 5 RCC of $\triangle N P V_{5,1}$ in Scenario 1 
Table 8 Values of the parameters varied in what-if analyses

\begin{tabular}{|c|c|c|c|c|}
\hline & \multicolumn{3}{|c|}{ Original value (left in Figs. 6 and 9) } & \multirow[t]{2}{*}{ Value used in what-if analysis } \\
\hline & $x_{\text {std }}$ & $x_{\min }$ & $x_{\max }$ & \\
\hline \multicolumn{5}{|l|}{ Scenario 1 (Fig. 6) } \\
\hline Manufacturing rate in continuous technology $v\left[\mathrm{~kg} \mathrm{~h}^{-1}\right]$ & 25 & 10 & 25 & $\begin{array}{l}19 \text { (middle) } \\
15 \text { (right) }\end{array}$ \\
\hline \multicolumn{5}{|l|}{ Scenario 2 (Fig. 9) } \\
\hline Manufacturing rate in continuous technology $v\left[\mathrm{~kg} \mathrm{~h}^{-1}\right]$ & 25 & 10 & 25 & 25 (middle \& right) \\
\hline Loss amount due to shut-down operation $m_{\text {loss,shut }}^{\text {continuous }}\left[\mathrm{kg} \mathrm{lot}^{-1}\right]$ & 5.00 & 1.00 & 20.0 & 2.50 (right) \\
\hline Loss amount due to start-up operation $m_{\text {loss,start }}^{\text {continous }}\left[\mathrm{kg} \mathrm{lot}^{-1}\right]$ & 12.5 & 1.00 & 20.0 & 6.25 (right) \\
\hline
\end{tabular}

same in both scenarios. The expert knowledge of the industrial coauthors was extensively used in determining the input parameters. The values associated with $C_{\mathrm{op}}$ were defined as in the previous study by this group [22]. We assumed that (i) there is a facility that is equipped with all three process alternatives, and (ii) the capacity of the facility is sufficient, i.e., $C_{\text {investment }}=0$ and $C_{\text {capaci- }}$ ty $(\tau)=0$. The uncertainties in the parameters related to $C_{\mathrm{dev}}$ were neglected, except for the uncertainty in the required quantity of clinical investigational drugs. A total of 85 uncertainty parameters was considered in both (see Table 3). The lot size and the material amount used in clinical development, which are the key input parameters for $C_{\text {develop, }}$ are presented in Table 7 . The probability that clinical development fails was also assumed, where $p_{2}$ and $p_{3}$ were 0.1 and 0.3 , respectively.

The results of Step 3 and the investigations on Q1 and Q2 are presented in the workflows for each scenario in Fig. 3. All the investigated alternatives fulfilled the first constraint of $E_{\boldsymbol{\theta}}(N P V(l))>0$ in Eq. (2).

\section{Scenario 1: inexpensive API and small demand}

The evaluation result of $\triangle N P V_{a, 1}$ in Scenario 1 is presented in Fig. 4. Alternative 1 (continuous technology and proportional dosage) was determined as the solution of the design problem (Eq. 2). The alternatives using continuous technology (alternatives 1 and 2) were more beneficial than those using batch technology (alternatives 3-6) regarding the mean. The continuous technology option required less development and operating costs because it needed less scale-up study as well as fewer operators and less manufacturing space. Proportional dosage (alternatives 1, 3, and 5) was more beneficial than a common dosage (alternatives 2, 4, and 6). The proportional dosage saved the mass of additives used in particular in the commercial production because the tablet size of the low dose was smaller in the proportional than in the common dosage. The difference between batch high-shear granulation (alternatives 3 and 4) and fluidized-bed granulation (alternatives 5 and 6) was because it was assumed that the high-shear granulation required less manufacturing space than fluidized-bed granulation. Overall, the decisions on whether to use "continuous or batch" and "proportional or common" were found to be more sensitive than those on "high-shear or fluidized-bed." Among the alternatives other than 1, alternative 5 had the highest possibility of $\triangle N P V_{a, 1}>0(23.0 \%)$. Thus, as an action for Q1, we investigated the superiority of alternative 1 over alternative 5 .

The result of the sensitivity analysis on $\triangle N P V_{5,1}$, where the top five sensitive parameters are displayed among the 85 parameters is presented in Fig. 5 (see Additional file 1 for more results). The manufacturing rate in continuous technology, $v$, was the most influential. Besides, many of the significant parameters were related to labor, and the parameters related to raw materials were not sensitive.

Based on the sensitivity analysis, a what-if analysis was performed on $\triangle N P V_{5}, 1$ by reducing the manufacturing rate, $v$. The varied parameters are shown in Table 8 , and the new result of $\triangle N P V_{a, 1}$ is shown in Fig. 6. When $v$ was

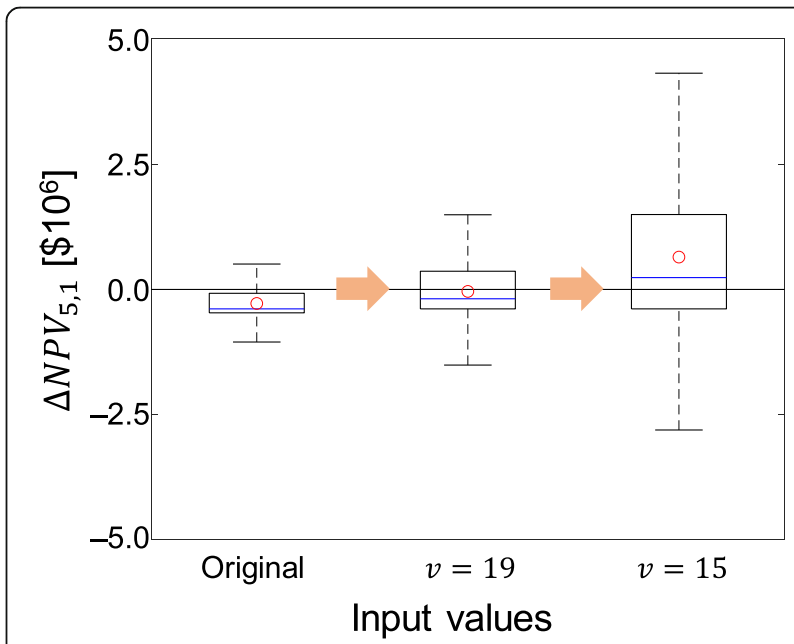

Fig. 6 What-if analysis in Scenario 1 with varying the manufacturing rate from the original (left) to $19 \mathrm{~kg} \mathrm{~h}^{-1}$ (middle) and to $15 \mathrm{~kg} \mathrm{~h}^{-1}$ (right) 


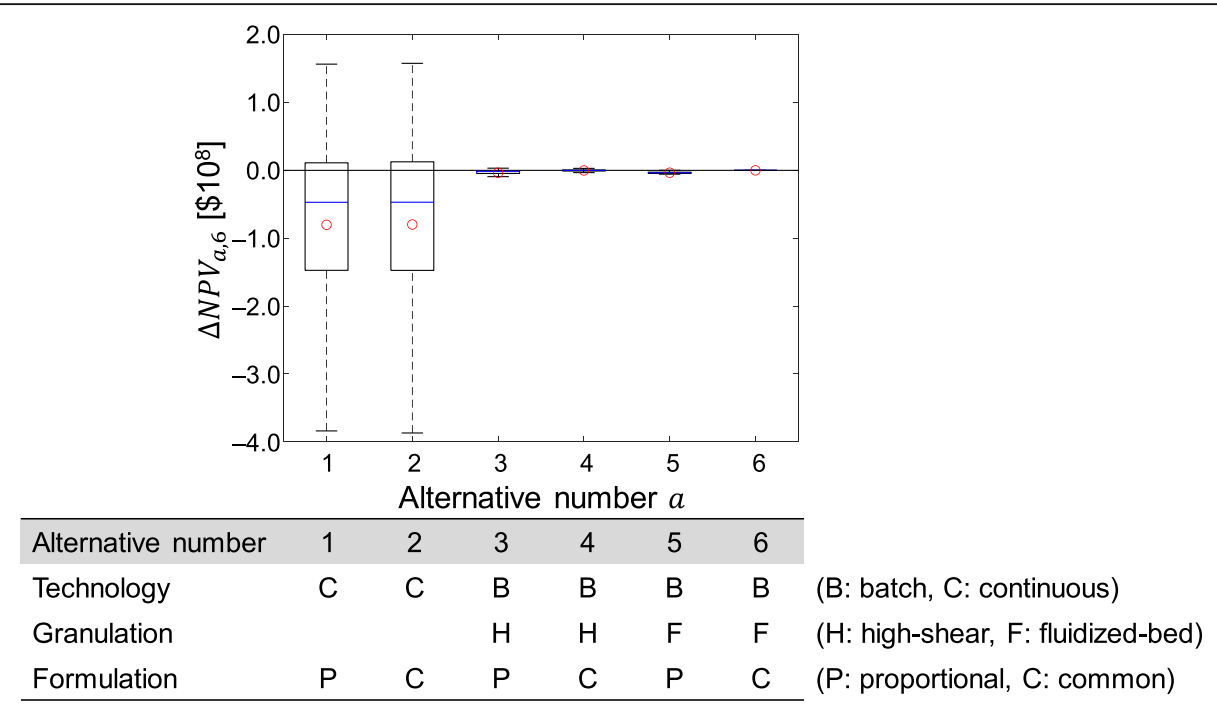

Fig. 7 Results of $\triangle N P V_{a, 6}$ in Scenario 2

$19 \mathrm{~kg} \mathrm{~h}^{-1}$, the mean of $\triangle N P V_{5,1}$ was nearly zero, and the probability of $\triangle N P V_{5}, 1>0$ was $35.2 \%$. A significant change in the distribution of $\triangle N P V_{5,1}$ was confirmed (the $p$-value for the Kolmogorov-Smirnov test was $5.00 \times 10^{-}$ ${ }^{3}$ ). When $v$ was reduced to $15 \mathrm{~kg} \mathrm{~h}^{-1}$, alternative 1 became inferior to alternative 5 regarding the mean, and the probability of $\triangle N P V_{5,1}>0$ was $53.2 \%$. The result showed again a significant change in $\triangle N P V_{5,1}$ (the $p$-value was $9.24 \times$ $\left.10^{-5}\right)$. Thus, to make the final decision on alternative 1 (Q2), the process characteristic for achieving high-speed manufacturing, e.g., the flowability of the materials, needs to be well understood.

\section{Scenario 2: expensive API and large demand}

The evaluation result of $\triangle N P V_{a, 6}$ in Scenario 2 is summarized in Fig. 7. Alternative 6 (batch technology, fluidizedbed granulation, and common dosage) showed the highest mean, and thus was determined as the solution for the design problem (Eq. 2). In contrast to Scenario 1, batch technology (alternatives 3-6) was better than continuous technology (alternatives 1 and 2) regarding the mean. In this study, the yield of continuous technology was assumed to be lower than that of batch technology [23]; therefore, the superiority of continuous technology decreased with increasing API price. The choice between continuous and batch largely affected the distributions because both technologies had many independent parameters related to material cost that were sensitive in Scenario 2. The common dosage (alternatives 2,4 , and 6) was better than the proportional dosage (alternatives 1,3 , and 5) this time. Adopting common dosage reduces the API weight percent in a low-dose formulation (see Table 5), which reduced the loss of expensive API in particular in the scale-up study and during investigational drug product manufacturing. Consequently, a common dosage became more economical, even though the input parameters were specified in such a way that common dosage required more experimental lots than proportional dosage (see Table 7). The superiority of fluidized-bed granulation to batch high-shear granulation remained the same as in Scenario 1. Alternative 2 showed $42.9 \%$ as the possibility of $\triangle N P V_{a, 6}>0$, which was the highest among the other alternatives. This result led us to compare alternatives 2 and 6 further regarding the superiority, as an action to Q1.

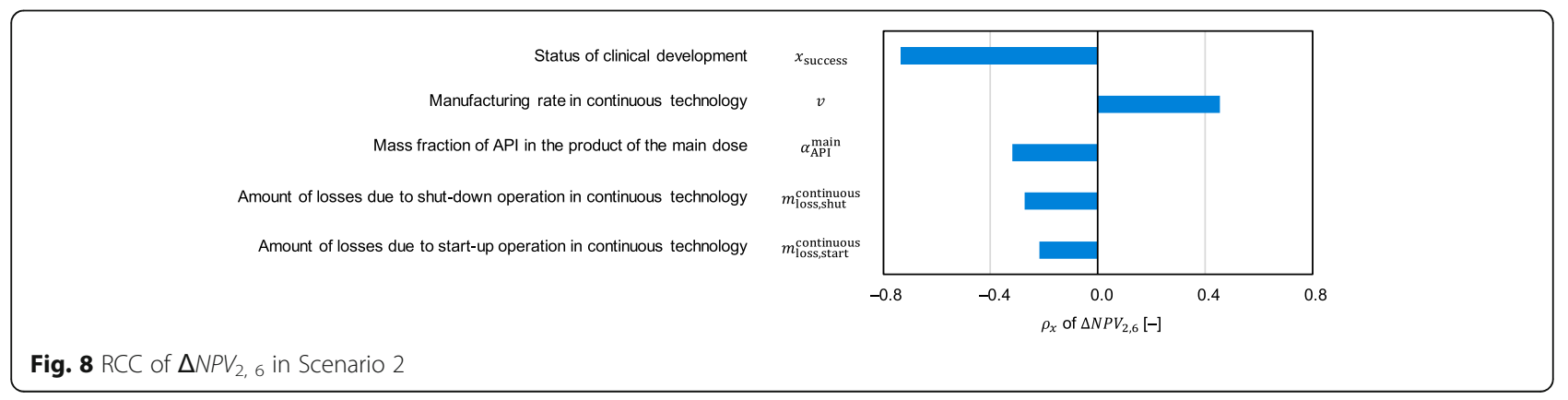




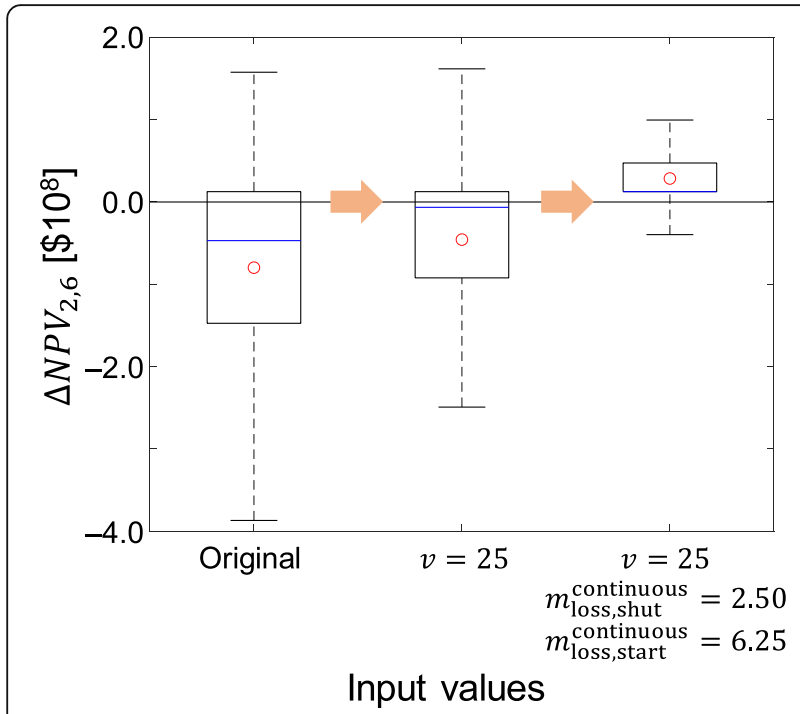

Fig. 9 What-if analysis in Scenario 2 with varying the manufacturing rate (middle and right) and loss amount (right) from the original (left)

The sensitivity analysis of $\triangle N P V_{2,6}$ in Scenario 2 is shown in Fig. 8 (see Additional file 1 for the detailed results). The RCC of the most influential parameter, which was the status of clinical development, was negative, i.e., if the development fails, continuous becomes lucrative.
This is because continuous was better than batch in terms of $C_{\mathrm{dev}}$, the tendency was the opposite in $C_{\mathrm{op}}$, and the impact of these values (summed over years) was huge. The possibility of $\triangle N P V_{2,6}>0$ was mostly due to the possibility of clinical development failure, which is not controllable in process design. Among the parameters in commercial production, material-related parameters were relevant, indicating the impact of the high API price assumed in Scenario 2.

A what-if analysis was performed on the sensitive parameters for $\triangle N P V_{2,6}$ (see Table 8 and Fig. 9). First, the manufacturing rate, $v$, which was originally distributed (see Table 8), was fixed at $25 \mathrm{~kg} \mathrm{~h}^{-1}$-the fastest, and thus most advantageous, condition for continuous technology. The distribution of $\triangle N P V_{2,6}$ did not change significantly (the $p$-value was 0.677 ), and the probability of $\triangle N P V_{2,6}>0$ increased from 42.9 to $48.5 \%$ (Fig. 9). Then, the sum of losses due to shut-down and start-up operations, $m_{\text {loss,shut }}^{\text {continuous }}$ and $m_{\text {loss start }}^{\text {continus }}$, was reduced to half $\left(8.75 \mathrm{~kg} \mathrm{lot}^{-1}\right)$ of the original standard value $(17.5 \mathrm{~kg}$ $\operatorname{lot}^{-1}$, see Table 8). This time, a significant change in $\triangle N P V_{2,}{ }_{6}$ (the $p$-value was $5.70 \times 10^{-10}$ ) was observed from the previous analysis (Fig. 9). The probability of $\triangle N P V_{2,6}>0$ increased to $90.9 \%$, and the mean was positive, indicating that alternative 6 became inferior to alternative 2. To conclude, alternative 6 (batch fluidized bed, proportional) can be selected in Scenario 2 .

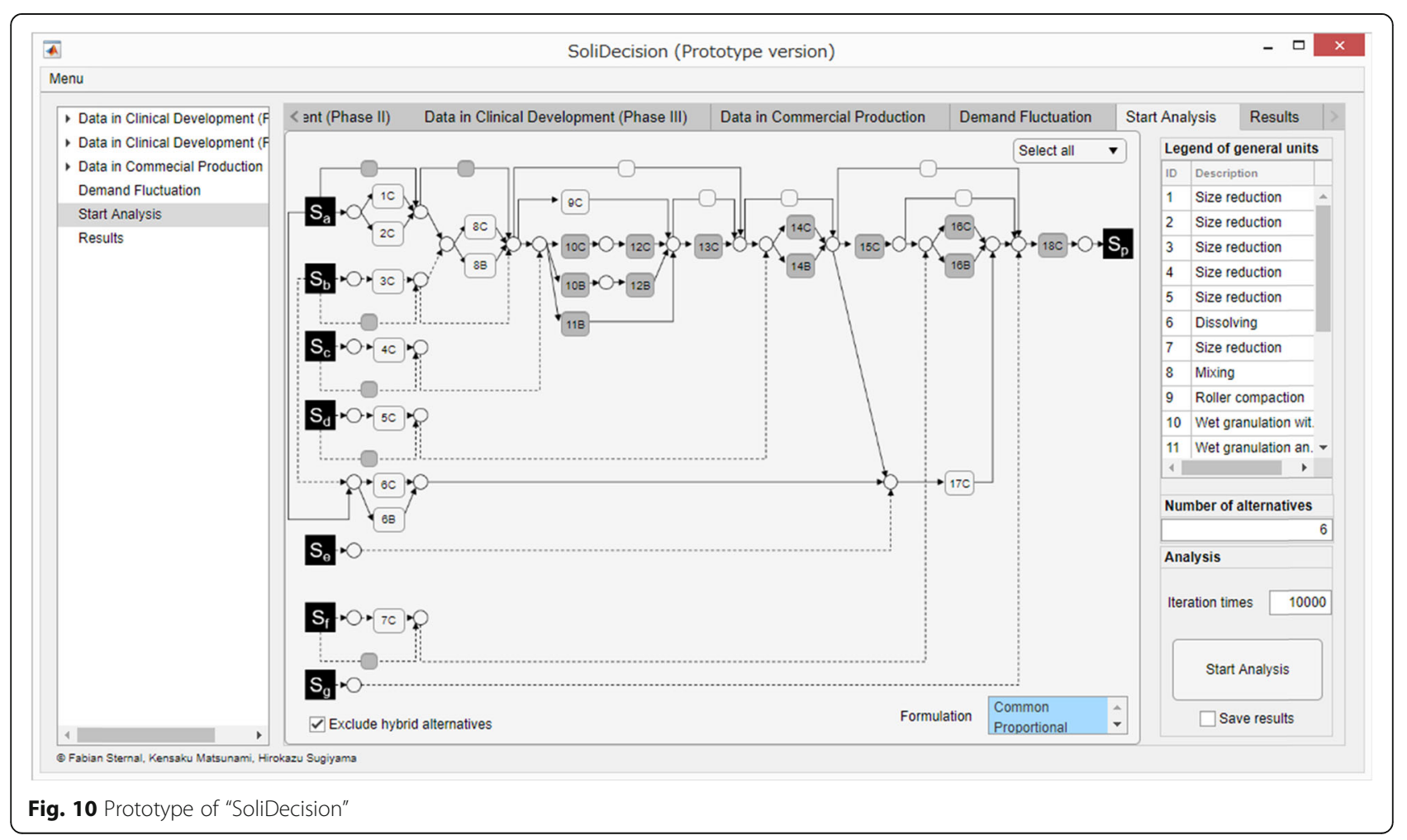


However, for alternative 2 it is highly likely to be superior in the event of clinical development failure, and when high-speed manufacturing with rapid start-up and shut-down is possible. These points need to be understood to make the final decision on alternative 2 (Q2).

\section{Software tool "SoliDecision"}

Efforts are currently being made for implementing the presented method as a software named "SoliDecision" (a combination of "solid" and "decision.") A prototype version was written in MATLAB R2019a (The MathWorks, Inc., Natick, MA, US) and was compiled as an executable (.exe) file using MATLAB App Designer. The compiled exe file constitutes a standalone desktop application that can be run without the MATLAB software environment. A graphical user interface of the prototype is shown in Fig. 10 (a version as of December 22, 2019) (see also Additional file 1). For the calculation of probabilities of NPV for six alternatives, it took $174 \mathrm{~s}$ using Intel $^{\circledR}$ Core $^{\mathrm{TM}}$ i7$8550 \mathrm{U}$ CPU @ $1.80 \mathrm{GHz}$ with 16.0 GB RAM memory. The prototype can reproduce the results presented above by following the steps of alternative generation, input parameter specification, and stochastic economic assessment. Some of the parameters, e.g., API price, can be varied. In the future, a full-licensed version will be developed where the users have the right to simulate various situations with freely varying the input parameters. The prototype (status December 22, 2019) will be available upon reasonable request to the corresponding author.

\section{Conclusions and outlook}

A new method for process synthesis and economic assessment for solid drug product manufacturing, considering continuous manufacturing as the prominent process alternative was presented. The method targeted the beginning of phase II as the decision stage. A superstructure was developed that covered 9452 options at the unit level, which was combined with two formulation strategy options. To assess the generated alternative, an MCS-based model was defined for calculating the NPV and for global sensitivity analysis. The workflow was demonstrated in a case study where two different scenarios regarding API price and demand were assumed. A practical finding was obtained that, when the demand and price are both low, the labor-related costs are dominant, and in the opposite case, the materialrelated costs become relevant. We also introduced the prototype version of the software "SoliDecision" that implemented the presented method for industrial application. The work highlighted the importance of developing new approaches to move away from the conventional empirical methodologies to a systematic and comprehensive development of optimal solutions. In the future, integration of other decision aspects, such as quality, could be pursued, toward multiobjective decisionmaking in drug development and manufacturing.

\section{Nomenclature}

Variables

$A$ Manufacturing area covered by $\operatorname{HVAC}\left[\mathrm{m}^{2}\right]$.

$C_{\text {capacity }}(\tau)$ Annual capacity cost $\left[\$ \mathrm{yr}^{-1}\right]$.

$C_{\mathrm{dev}}(\tau)$ Development cost in $\tau$ years after the decision stage $\left[\$ \mathrm{yr}^{-1}\right]$.

$C_{\text {disposal }}$ Cost to dispose of a unit amount of loss $\left[\$ \mathrm{~kg}^{-}\right.$ 1 ]. $C_{\mathrm{drug}}^{h}$ Selling price of drugs of formulation $h$ [\$ (dosage unit) ${ }^{-1}$.

$C_{\text {HVAC }}$ HVAC cost $\left[\$ \mathrm{~m}^{-2} \mathrm{~h}^{-1}\right]$.

$C_{\text {invest }}$ Investment cost $\left[\$ \mathrm{yr}^{-1}\right]$.

$C_{\text {labor }}$ Labor rate $\left[\$\right.$ person $\left.^{-1} \mathrm{~h}^{-1}\right]$.

$C_{\text {labor,clinical }}^{j}$ Labor cost of investigational drug production in phase $j\left[\$ \mathrm{yr}^{-1}\right]$.

$C_{\text {labor,process }}^{j}$ Labor cost of formulation and process development in phase $j\left[\$ \mathrm{yr}^{-1}\right]$.

$C_{\text {labor,scale }}^{j}$ Labor cost of scale-up study in phase $j\left[\$ \mathrm{yr}^{-}\right.$ $1]$.

$C_{\text {material,clinical }}^{j}$ Material cost of investigational drug production in phase $j\left[\$ \mathrm{yr}^{-1}\right]$.

$C_{\text {material, } k}$ Cost of raw material $k\left[\$ \mathrm{~kg}^{-1}\right]$.

$C_{\text {material,process }}^{j}$ Material cost of formulation and process development in phase $j\left[\$ \mathrm{yr}^{-1}\right]$.

$C_{\text {material.scale }}^{j}$ Material cost of scale-up study in phase $j$ [\$ $\left.\mathrm{yr}^{-1}\right]$.

$C_{\text {material, solvent }}$ Cost of solvent $\left[\$ \mathrm{~kg}^{-1}\right]$.

$C_{\text {op }}(\tau)$ Operating cost in $\tau$ years after the decision stage $\left[\$ \mathrm{yr}^{-1}\right]$.

$C_{\text {sales }}(\tau)$ Sales in $\tau$ years after the decision stage [ $\left.\$ \mathrm{yr}^{-1}\right]$.

$C_{\text {test }}(\tau)$ Cost of materials for testing $\left[\$ \mathrm{yr}^{-1}\right]$.

$d$ Difference between the ranks of $x$ and $\triangle N P V_{l_{1}, l_{2}}[-]$.

$m^{h}$ Product weight for the formulation $h$ [ kg (dosage

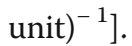

$M_{\text {loss, } k}(\tau)$ Loss amount of material $k\left[\mathrm{~kg} \mathrm{yr}^{-1}\right]$.

$m_{\text {loss, comp }}$ Loss amount caused by compression testing in compression $\left[\mathrm{kg} \mathrm{lot}{ }^{-1}\right]$.

$m_{\text {loss,feeder }}^{\text {continuous }}$ Loss amount remaining in the feeder in continuous technology [kg campaign ${ }^{-1}$ ].

$m_{\text {loss,sample, } u}^{\text {tech }}$ Loss amount caused by sampling in unit $u$ in technology tech $\left[\mathrm{kg} \mathrm{lot}{ }^{-1}\right]$.

$m_{\text {loss,shut }}^{\text {continuous }}$ Loss amount due to shut-down operation in continuous technology [ $\left.\mathrm{kg} \operatorname{lot}^{-1}\right]$.

$m_{\text {loss,start }}^{\text {continuous }}$ Loss amount due to start-up operation in continuous technology [kg lot $\left.{ }^{-1}\right]$. 
$m_{\text {loss }, \text { stick, } u}^{\text {tech }}$ Loss amount caused by sticking in unit $u[\mathrm{~kg}$ campaign $^{-1}$ ].

$M_{\text {product, } k}(\tau)$ Annual amount of material $k$ used to make the product $\left[\mathrm{kg} \mathrm{yr}^{-1}\right]$.

$M_{\text {solvent }}(\tau)$ Annual amount of solvent used $\left[\mathrm{kg} \mathrm{yr}^{-1}\right]$.

$N$ Number of iterations (dataset) $[-]$.

$N_{\text {campaign }}^{\text {tech }}$ Number of lots in one campaign manufacturing in technology tech [lot campaign ${ }^{-1}$ ].

$N_{\text {demand }}^{h}(\tau)$ Demand amount in $\tau$ years after the decision stage of formulation $h$ [(dosage unit) $\mathrm{yr}^{-1}$ ].

$N_{\text {demand }}^{\text {max } h}$ Peak demand amount for formulation $h[($ dosage unit) $\mathrm{yr}^{-1}$ ].

$n_{\mathrm{p} \text {-cleaning }}^{\text {tech }}$ Number of operators in cleaning in technology tech [person].

$n_{\mathrm{p}-u}^{\text {tech }}$ Number of operators in unit $u$ in technology tech [person].

NPV Net present value [\$].

$p_{\text {LHS }}$ Value sampled based on LHS [-].

$p_{2}$ Probability that the clinical development fails at phase II $[-]$.

$p_{3}$ Probability that the clinical development fails at phase

III [-].

$r$ Interest rate [-].

$t_{\text {campaign }}^{\text {tech }}$ Total time needed for one campaign manufacturing in technology tech [h campaign ${ }^{-1}$ ].

$T_{\text {cleaning }}^{\text {tech }}$ Required work time of cleaning in technology tech $\left[\right.$ h campaign $\left.^{-1}\right]$.

$T_{\text {HVAC }}(\tau)$ HVAC running time $\left[\mathrm{h} \mathrm{yr}^{-1}\right]$.

$T_{\text {pass }}$ Required time for passing through all units in continuous technology [h].

$T_{u}^{\text {tech }}$ Required work time of unit $u$ in technology tech [h $\operatorname{lot}^{-1}$.

$v$ Manufacturing rate in continuous technology $\left[\mathrm{kg} \mathrm{h}^{-1}\right]$.

$W_{\text {cleaning }}(\tau)$ Annual person-hours for cleaning [person $h$ $\left.\mathrm{yr}^{-1}\right]$.

$W_{\text {manufacturing }}(\tau)$ Annual person-hours for manufacturing [person $\mathrm{h} \mathrm{yr}^{-1}$ ].

$W_{\text {PAT }}(\tau)$ Annual person-hours for PAT maintenance [person $\mathrm{h} \mathrm{yr}^{-1}$ ].

$W_{\text {testing }}(\tau)$ Annual person-hours for testing [person $h$ $\left.\mathrm{yr}^{-1}\right]$.

$x_{\max }$ Maximum value of input parameter $x$.

$x_{\min }$ Minimum value of input parameter $x$

$x_{\text {sample }}$ Value used for MCS

$x_{\text {std }}$ Standard value of input parameter $x$

$x_{\text {success }}$ Status of clinical development [-]

$\alpha_{k}^{h}$ Composition ratio of material $k$ in the product of formulation $h[-]$

$\triangle N P V_{l_{1}, l_{2}}$ Difference of $N P V$ between alternatives $l_{1}$ and $l_{2}[\$]$

$\rho_{x}$ Spearman RCC for parameter $x[-]$ $\tau$ Time period after the decision stage [yr]

$\tau_{\text {inv }}$ Time period from the decision stage to the investment [yr]

$\tau_{j}$ Time period from the decision stage to the clinical trials at phase $j[\mathrm{yr}]$

$\tau_{\text {lau }}$ Time period from the decision stage to the product launch [yr]

$\tau_{\text {prod }}$ Time period from the decision stage to the end of commercial production [yr]

Functions

$f_{1}$ PDF for continuous variables

$f_{2}$ PDF for integer variables

$f_{3}$ PDF for categorical variables

Suffixes

$a, l, l_{1}, l_{2}$ Alternatives [-]

$h$ Dose (main, low) [-]

j Clinical phase [-]

$k$ Material [-]

$u$ Manufacturing unit (gran, blend, com, coat) [-]

\section{Supplementary information}

Supplementary information accompanies this paper at https://doi.org/10. 1186/s42480-020-0028-2.

Additional file 1. . This file presents calculation of the number of alternatives in a superstructure, details about the case study, and the contents of "SoliDecision."

\section{Abbreviations}

API: Active pharmaceutical ingredient; CFD: Computational fluid dynamics; DEM: Discrete element method; FDA: The US Food and Drug Administration; HVAC: Heating, ventilation, and air conditioning; LHS: Latin hypercube sampling; MCS: Monte Carlo simulation; NPV: Net present value; PAT: Process analytical technology; PBM: Population balance model; PDF: Probability density function; PSE: Process systems engineering; RCC: Rank correlation coefficient

\section{Acknowledgements}

The authors acknowledge Prof. Masahiko Hirao, Dr. Eri Amasawa, and Dr. Sara Badr of The University of Tokyo for useful discussions. The technical support by Mr. Tomohiko Higashi from MathWorks is gratefully acknowledged. K. M. would like to express gratitude to the Leading Graduate Schools Program,

"Global Leader Program for Social Design and Management," by the Ministry of Education, Culture, Sports, Science and Technology for their support.

\section{Authors' contributions}

$\mathrm{KM}, \mathrm{KY}, \mathrm{ST}, \mathrm{HN}$, and HS conceived the initial idea. HS and KM designed the study. KM, FS, and HS developed the theory and performed the calculations. KY, ST, and HN provided industrial information/data/insights. KM drafted the manuscript, and FS, KY, ST, HN, and HS reviewed and edited the draft. All authors have read and approved the final manuscript.

\section{Funding}

The study was funded by a research grant from Daiichi Sankyo Co., Ltd. H. S. used the financial support by a Grant-in-Aid for Young Scientists (A) from the Japan Society for the Promotion of Science (JSPS) [Grant number 17H04964] for conducting part of this research. K. M. used the financial support of a Grant-in-Aid for JSPS Research Fellows [Grant number 18 J22793] for conducting part of this research. 


\section{Availability of data and materials}

We present the key input parameter values and model equations that are necessary to understand the results and to draw the conclusion. Because the presented method is now being implemented in a licensed version of the software, we are not presenting all parameter values /subequations. The presented prototype version (status December 22, 2019) will be available upon reasonable request to the corresponding author.

\section{Ethics approval and consent to participate}

Not applicable.

\section{Consent for publication}

Not applicable.

\section{Competing interests}

The study was funded by a research grant from Daiichi Sankyo Co., Ltd.

\section{Author details}

'Department of Chemical System Engineering, The University of Tokyo, 7-3-1 Hongo, Bunkyo-ku, Tokyo 113-8656, Japan. ${ }^{2}$ Department of Chemical and Bioengineering, Friedrich-Alexander-University Erlangen-Nürnberg, Cauerstrasse 4, 91058 Erlangen, Germany. ${ }^{3}$ Formulation Technology Research Laboratories, Pharmaceutical Technology Division, Daiichi Sankyo Co., Ltd., 1-12-1, Shinomiya, Hiratsuka, Kanagawa 254-0014, Japan.

Received: 9 October 2019 Accepted: 12 January 2020

Published online: 12 February 2020

\section{References}

1. FDA. New drugs at FDA: CDER's new molecular entities and new therapeutic biological products | FDA. https://www.fda.gov/drugs/ development-approval-process-drugs/new-drugs-fda-cders-new-molecularentities-and-new-therapeutic-biological-products. Accessed 16 Sept 2019.

2. Zhong H, Chan G, Hu Y, Hu H, Ouyang D. A comprehensive map of FDAapproved pharmaceutical products. Pharmaceutics. 2018;10:263. https://doi. org/10.3390/pharmaceutics10040263.

3. lerapetritou M, Muzzio F, Reklaitis G. Perspectives on the continuous manufacturing of powder-based pharmaceutical processes. AICHE J. 2016; 62:1846-62. https://doi.org/10.1002/aic.15210.

4. Mullin R. Off the drawing board. C EN Glob Enterp. 2019;97:28-33. https:// doi.org/10.1021/cen-09717-cover.

5. Lee SL, O'Connor TF, Yang X, Cruz CN, Chatterjee S, Madurawe RD, et al. Modernizing pharmaceutical manufacturing: from batch to continuous production. J Pharm Innov. 2015;10:191-9. https://doi.org/10.1007/s12247015-9215-8.

6. Matsuda Y. Global regulatory landscape. AAPS PharmSciTech. 2019;20:2. https://doi.org/10.1208/s12249-018-1230-X.

7. Nasr MM, Krumme M, Matsuda Y, Trout BL, Badman C, Mascia S, et al. Regulatory perspectives on continuous pharmaceutical manufacturing: moving from theory to practice. J Pharm Sci. 2017;106:3199-206. https://doi. org/10.1016/.j.xphs.2017.06.015.

8. Helal NA, Elnoweam O, Eassa HA, Amer AM, Eltokhy MA, Helal MA, et al. Integrated continuous manufacturing in pharmaceutical industry: current evolutionary steps toward revolutionary future. Pharm Pat Anal. 2019. https://doi.org/10.4155/ppa-2019-0011.

9. Chaudhury A, Barrasso D, Pandey P, Wu H, Ramachandran R. Population balance model development, validation, and prediction of CQAs of a highshear wet granulation process: towards QbD in drug product pharmaceutical manufacturing. J Pharm Innov. 2014;9:53-64. https://doi.org/ 10.1007/s12247-014-9172-7.

10. Vreman AW, van Lare CE, Hounslow MJ. A basic population balance model for fluid bed spray granulation. Chem Eng Sci. 2009;64:4389-98. https://doi. org/10.1016/j.ces.2009.07.010.

11. Van Hauwermeiren D, Verstraeten M, Doshi P, am Ende MT, Turnbull N, Lee $\mathrm{K}$, et al. On the modelling of granule size distributions in twin-screw wet granulation: calibration of a novel compartmental population balance model. Powder Technol. 2019;341:116-25. https://doi.org/10.1016/j.powtec 2018.05.025.

12. Tamrakar A, Ramachandran R. CFD-DEM-PBM coupled model development and validation of a 3D top-spray fluidized bed wet granulation process.
Comput Chem Eng. 2019;125:249-70. https://doi.org/10.1016/j. compchemeng.2019.01.023.

13. Hsu S-H, Reklaitis GV, Venkatasubramanian V. Modeling and control of roller compaction for pharmaceutical manufacturing. Part I: process dynamics and control framework. J Pharm Innov. 2010;5:14-23. https://doi.org/10.1007/ s12247-010-9076-0.

14. Reynolds GK, Campbell Jl, Roberts RJ. A compressibility based model for predicting the tensile strength of directly compressed pharmaceutical powder mixtures. Int J Pharm. 2017;531:215-24. https://doi.org/10.1016/j. ijpharm.2017.08.075.

15. Boehling P, Toschkoff $G$, Just $S$, Knop K, Kleinebudde P, Funke A, et al. Simulation of a tablet coating process at different scales using DEM. Eur J Pharm Sci. 2016;93:74-83. https://doi.org/10.1016/j.ejps.2016.08. 018.

16. García-Muñoz S, Butterbaugh A, Leavesley I, Manley LF, Slade D, Bermingham S. A flowsheet model for the development of a continuous process for pharmaceutical tablets: an industrial perspective. AICHE J. 2018; 64:511-25. https://doi.org/10.1002/aic.15967.

17. Boukouvala F, Niotis V, Ramachandran R, Muzzio FJ, lerapetritou MG. An integrated approach for dynamic flowsheet modeling and sensitivity analysis of a continuous tablet manufacturing process. Comput Chem Eng. 2012;42:30-47. https://doi.org/10.1016/j.compchemeng.2012.02.015.

18. Metta N, Ghijs M, Schäfer E, Kumar A, Cappuyns P, Van Assche I, et al. Dynamic flowsheet model development and sensitivity analysis of a continuous pharmaceutical tablet manufacturing process using the wet granulation route. Processes. 2019;7:234. https://doi.org/10.3390/pr7040234.

19. Singh $R$, lerapetritou $M$, Ramachandran $R$. An engineering study on the enhanced control and operation of continuous manufacturing of pharmaceutical tablets via roller compaction. Int J Pharm. 2012;438:307-26. https://doi.org/10.1016/j.jpharm.2012.09.009.

20. Schaber SD, Gerogiorgis DI, Ramachandran R, Evans JMB, Barton PI, Trout BL. Economic analysis of integrated continuous and batch pharmaceutical manufacturing: a case study. Ind Eng Chem Res. 2011;50:10083-92. https:// doi.org/10.1021/ie2006752.

21. Aigner I, Hsiao W-K, Dujmovic D, Stegemann S, Khinast J. Methodology for economic and technical comparison of continuous and batch processes to enhance early stage decision-making. In: Kleinebudde P, Khinast J, Rantanen J, editors. Continuous manufacturing of pharmaceuticals. Chichester: Wiley; 2017. p. 485-505. https://doi.org/10.1002/9781119001348.ch14.

22. Matsunami K, Miyano T, Arai H, Nakagawa H, Hirao M, Sugiyama H. Decision support method for the choice between batch and continuous technologies in solid drug product manufacturing. Ind Eng Chem Res. 2018; 57:9798-809. https://doi.org/10.1021/acs.iecr.7b05230.

23. Matsunami K, Nagato T, Hasegawa K, Sugiyama H. A large-scale experimental comparison of batch and continuous technologies in pharmaceutical tablet manufacturing using ethenzamide. Int J Pharm. 2019; 559:210-9. https://doi.org/10.1016/j.ijpharm.2019.01.028.

24. Sundaramoorthy A, Evans JMB, Barton PI. Capacity planning under clinical trials uncertainty in continuous pharmaceutical manufacturing, 1: mathematical framework. Ind Eng Chem Res. 2012;51:13692-702. https://doi. org/10.1021/ie300324h.

25. Sundaramoorthy A, Li X, Evans JMB, Barton PI. Capacity planning under clinical trials uncertainty in continuous pharmaceutical manufacturing, 2: solution method. Ind Eng Chem Res. 2012;51:13703-11. https://doi.org/10. 1021/ie3003254.

26. Marques CM, Moniz S, de Sousa JP, Barbosa-Póvoa AP. A simulationoptimization approach to integrate process design and planning decisions under technical and market uncertainties: a case from the chemicalpharmaceutical industry. Comput Chem Eng. 2017;106:796-813. https://doi. org/10.1016/j.compchemeng.2017.04.008.

27. Marques CM, Moniz S, de Sousa JP. Strategic decision-making in the pharmaceutical industry: a unified decision-making framework. Comput Chem Eng. 2018;1 19:171-89. https://doi.org/10.1016/j.compchemeng.2018. 09.010 .

28. Walther J, Godawat R, Hwang C, Abe Y, Sinclair A, Konstantinov K. The business impact of an integrated continuous biomanufacturing platform for recombinant protein production. J Biotechnol. 2015;213:3-12. https://doi. org/10.1016/j.jbiotec.2015.05.010.

29. Türkay M, Grossmann IE. Logic-based MINLP algorithms for the optimal synthesis of process networks. Comput Chem Eng. 1996;20:959-78. https:// doi.org/10.1016/0098-1354(95)00219-7. 
30. Kondili E, Pantelides CC, Sargent RWH. A general algorithm for short-term scheduling of batch operations-I. MILP formulation. Comput Chem Eng. 1993;17:211-27. https://doi.org/10.1016/0098-1354(93)80015-F.

31. Yeomans H, Grossmann IE. A systematic modeling framework of superstructure optimization in process synthesis. Comput Chem Eng. 1999; 23:709-31. https://doi.org/10.1016/S0098-1354(99)00003-4.

32. Quaglia A, Gargalo CL, Chairakwongsa S, Sin G, Gani R. Systematic network synthesis and design: problem formulation, superstructure generation, data management and solution. Comput Chem Eng. 2015;72:68-86. https://doi. org/10.1016/j.compchemeng.2014.03.007.

33. Bertran MO, Frauzem R, Sanchez-Arcilla AS, Zhang L, Woodley JM, Gani R. A generic methodology for processing route synthesis and design based on superstructure optimization. Comput Chem Eng. 2017;106:892-910. https:// doi.org/10.1016/j.compchemeng.2017.01.030.

34. Matsunami K, Tanabe S, Nakagawa H, Hirao M, Sugiyama H. Economic evaluation of batch and continuous manufacturing technologies for solid drug products during clinical development. Comput Aided Chem Eng. 2018;44:2131-6. https://doi.org/10.1016/B978-0-444-64241-7.50350-5.

35. Wu W, Henao CA, Maravelias CT. A superstructure representation, generation, and modeling framework for chemical process synthesis. AICHE J. 2016;62:3199-214. https://doi.org/10.1002/aic.15300.

36. El-Halwagi MM. Sustainable design through process integration: fundamentals and applications to industrial pollution prevention, resource conservation, and profitability enhancement. Waltham: ButterworthHeinemann; 2012.

37. Kokonendji CC, Zocchi SS. Extensions of discrete triangular distributions and boundary bias in kernel estimation for discrete functions. Stat Probab Lett. 2010;80:1655-62. https://doi.org/10.1016/j.spl.2010.07.008.

38. Mckay MD, Beckman RJ, Conover WJ. A comparison of three methods for selecting values of input variables in the analysis of output from a computer code. Technometrics. 2000;42:55-61. https://doi.org/10.1080/ 00401706.2000.10485979.

39. Spearman C. The proof and measurement of association between two things. Am J Psychol. 1904;15:72-101. https://doi.org/10.2307/1412159.

40. Zar JH. Significance testing of the Spearman rank correlation coefficient. J Am Stat Assoc. 1972;67:578-80. https://doi.org/10.1080/01621459.1972 10481251.

41. Massey FJ. The Kolmogorov-Smirnov test for goodness of fit. J Am Stat Assoc. 1951:46:68-78. https://doi.org/10.1080/01621459.1951.10500769.

42. Hesamian G, Chachi J. Two-sample Kolmogorov-Smirnov fuzzy test for fuzzy random variables. Stat Pap. 2015;56:61-82. https://doi.org/10.1007/s00362013-0566-2.

43. Casola G, Sugiyama H, Siegmund C, Mattern M. Uncertainty-conscious methodology for process performance assessment in biopharmaceutical drug product manufacturing. AICHE J. 2018;64:1272-84. https://doi.org/10. 1002/aic.16020.

\section{Publisher's Note}

Springer Nature remains neutral with regard to jurisdictional claims in published maps and institutional affiliations.

Ready to submit your research? Choose BMC and benefit from:

- fast, convenient online submission

- thorough peer review by experienced researchers in your field

- rapid publication on acceptance

- support for research data, including large and complex data types

- gold Open Access which fosters wider collaboration and increased citations

- maximum visibility for your research: over $100 \mathrm{M}$ website views per year

At $\mathrm{BMC}$, research is always in progress.

Learn more biomedcentral.com/submissions 